\title{
How do nuclei couple to the magnetic moment of a paramagnetic center? A new theory at the gauntlet of the experiments
}

Linda Cerofolini, ${ }^{1 \neq}$ José Malanho Silva, ${ }^{1,2,3 \neq}$ Enrico Ravera, ${ }^{1,4}$ Maurizio Romanelli, ${ }^{5}$ Carlos F.G.C. Geraldes, ${ }^{2}$ Anjos L. Macedo, ${ }^{3}$ Marco Fragai, ${ }^{1,4}$ Giacomo Parigi, ${ }^{1,4}$ Claudio Luchinat ${ }^{1,4 *}$

${ }^{1}$ Magnetic Resonance Center (CERM), University of Florence, via Sacconi 6, Sesto Fiorentino, Italy; ${ }^{2}$ Department of Life Sciences and Coimbra Chemistry Center, University of Coimbra, Coimbra, Portugal; ${ }^{3}$ UCIBIO-Requimte, Faculty of Sciences and

Technology, Universidade NOVA de Lisboa, Caparica, Portugal; ${ }^{4}$ Department of Chemistry, University of Florence, Sesto Fiorentino, Italy and ${ }^{5}$ Department of Earth Sciences, University of Florence, Italy. 
The human carbonic anhydrase II (hCAII) triple mutant (H3N, H4N, H64N) was cloned following a standard PCR protocol. For the H3N and H4N mutations the used primers were: forward: 5'- GA AGG AGA TAT ACC ATG GCC AAT AAC TGG GGG TAC GGC AAA CAC -3' and reverse: GTG TTT GCC GTA CCC CCA GTT ATT GGC CAT GGT ATA TCT CCT TC -3'. For the H64N mutation the primers were : forward: 5'- C CTG AGG ATC CTC AAC AAT GGT AAT GCT TTC AAC GTG GAG TTT G -3' and reverse. 5'- C AAA CTC CAC GTT GAA AGC ATT ACC ATT GTT GAG GAT CCT CAG G -3'. The sequence of the triple mutant hCAII was confirmed by sequencing.

The plasmid, containing the sequence of the triple mutant of hCAII, was transformed into E. coli BL21-CodonPlus (DE3)-RIPL cells using a standard heat shock protocol. Afterwards, $1 \mathrm{~mL}$ of LB was added to the cell culture and it was incubated at $37^{\circ} \mathrm{C}, 200 \mathrm{rpm}$ for $1 \mathrm{~h} 30^{\prime}$. The culture was plated in LB-Agar plates supplemented with ampicillin and chloramphenicol and incubated $37^{\circ} \mathrm{C}$ overnight. The next day, E. coli colonies were inoculated in 6 $\mathrm{x} 10 \mathrm{~mL} \mathrm{LB}$ media supplemented with ampicillin and chloramphenicol and incubated for 8 hours at $37^{\circ} \mathrm{C}, 200 \mathrm{rpm}$. Afterwards each $10 \mathrm{~mL}$ culture were transferred to $1 \mathrm{~L} \mathrm{LB}$ media ( 6 liters of LB total) supplemented with ampicillin and chloramphenicol and incubated at $37^{\circ} \mathrm{C}, 160 \mathrm{rpm}$ overnight. In the following day, cells were harvested at $4000 \mathrm{rpm}$ for 15 minutes. The cells harvested from $2 \mathrm{~L}$ of $\mathrm{LB}$ were resuspended in $1 \mathrm{~L} \mathrm{M} 9 \mathrm{media}$, for a total of $3 \mathrm{~L}$ of M9, supplemented with $\mathrm{CaCl} 2, \mathrm{ZnSO} 4, \mathrm{MgSO} 4$, ampicillin, chloramphenicol, $3 \mathrm{mg} / \mathrm{L}$ of glucose and $1.2 \mathrm{mg} / \mathrm{L}^{15} \mathrm{~N}_{-} \mathrm{NH}_{4} \mathrm{SO}$. Cultures were incubated for 1 hour at $37^{\circ} \mathrm{C}, 160 \mathrm{rpm}$. Protein expression was induced with $1 \mathrm{mM}$ IPTG. Protein expression was halted after 5 hours of induction and the cells were harvested at $7500 \mathrm{rpm}$ and stored at $-20^{\circ} \mathrm{C}$. The cell paste was resuspended in $200 \mathrm{~mL}$ of $20 \mathrm{mM}$ Tris-SO4, $500 \mu \mathrm{M} \mathrm{ZnSO} 4, \mathrm{pH} 8 . \mathrm{Cells}$ were sonicated 10 times ( 30 seconds ON, 3 minutes OFF, power $70 \%$ ) on ice and then it was ultracentrifuged at $40000 \mathrm{rpm}$ for $40 \mathrm{minutes}$ at $4{ }^{\circ} \mathrm{C}$. The protein was purified with a two-step purification protocol, which comprises of a HisTrap and Size Exclusion Chromatographies.

The copper (II) derivative was obtained from the zinc(II) adduct by a demetallation/metalation approach. For demetallation, a solution containing $200 \mathrm{mM}$ sodium phosphate, $50 \mathrm{mM}$ pyridine-2,6-dicarboxylic acid (PDA), $\mathrm{pH} 7$ was added to the protein solution and incubated overnight at $4{ }^{\circ} \mathrm{C}$. After the demetallation, the apo-hCAII triple mutant was buffered exchanged to $10 \mathrm{mM} \mathrm{HEPES,} \mathrm{pH} 5.1$ and then to $\mathrm{pH} 8$ using $10,000 \mathrm{MWCO}$ Amicon ultracentrifugation devices.

The paramagnetic copper (II)-hCAII triple mutant was prepared by titration of apo-hCAII triple mutant (1.5 mM in $10 \mathrm{mM} \mathrm{HEPES,} \mathrm{pH} 8$ ) with copper (II) sulfate solution monitored with $1 \mathrm{D}^{1} \mathrm{H}$ and $2 \mathrm{D}^{1} \mathrm{H}_{-}{ }^{15} \mathrm{~N}$ HSQC solution NMR spectra at $298 \mathrm{~K}$. The buffer was then exchanged to $10 \mathrm{mM}$ HEPES pH 6 and a solution of oxalate was added to the protein solution to reach a final concentration of $2.5 \mathrm{mM}$ of oxalate. The zinc(II) diamagnetic reference was prepared following the same protocol.

\section{NMR measurements}

Solution $2 \mathrm{D}{ }^{1} \mathrm{H}-{ }^{15} \mathrm{~N}$ HSQC NMR spectra of the ${ }^{15} \mathrm{~N}$ isotopically enriched zinc(II) and copper(II) substituted triple mutant of carbonic anhydrase II, for the evaluation of PCS, were recorded on a Bruker AVANCE III NMR spectrometer, operating at $950 \mathrm{MHz}{ }^{1} \mathrm{H}$ Larmor frequency, equipped with a triple resonance cryo-probe. Protein samples were in water buffered solution [10 mM HEPES, $\mathrm{pH}$ 6] containing $2.5 \mathrm{mM}$ oxalate and with protein concentrations of $1.5 \mathrm{mM} .2 \mathrm{D}{ }^{1} \mathrm{H}_{-}{ }^{15} \mathrm{~N}$ HSQC NMR spectra on the zinc(II) and copper(II) substituted triple mutant of carbonic anhydrase II were acquired at 303, 298, 293 and $288 \mathrm{~K}$.

All the spectra were processed with the Bruker TopSpin software package, and analyzed with the program CARA (the program can be downloaded for free from www.nmr.ch). ${ }^{1}$

The assignment of the diamagnetic [zinc(II)] spectra was previously published, ${ }^{2}$ whereas the paramagnetic spectra were easily reassigned, because of the small shift, starting from the diamagnetic reference. The PCSs were calculated from the difference in the value of chemical shift between the paramagnetic [copper(II)] and diamagnetic [zinc(II)] spectrum of the protein.

The PCSs $\Delta \chi$ tensor was evaluated with the program FANTEN ${ }^{3}$ on the We-NMR/West-Life web portals from the best fit of 116 experimental PCSs on the protein structure (PDB code: $3 \mathrm{KS} 3)^{4}$

EPR measurements and fit

The EPR spectra were acquired in solution at room temperature on a BRUKER ELEXSYS EPR spectrometer operating at X-band equipped with a super-high sensitivity probehead. The modulation frequency was set to $100 \mathrm{kHz}$; the microwave frequency was set to $9.843 \mathrm{GHz}$. Centerfield was set to $330 \mathrm{mT}$ and the total field sweep was $200 \mathrm{mT} ; 3$ scans were taken.

The fit of the EPR spectrum was performed using EasySpin. ${ }^{5}$

\section{Analysis of PCSs}

The analysis of the PCSs for the copper(II) bound form of the type-1 copper protein pea plastocyanin (taken from Ubbink, M.; Lian, L. Y.; Modi, S.; Evans, P. A.; Bendall, D. S., Analysis of the 1H-NMR chemical shifts of $\mathrm{Cu}(\mathrm{I})$-, Cu(II)-and Cd-substituted pea plastocyanin. Metal-dependent differences in the hydrogen-bond network around the copper site. Eur. J. Biochem 1996, 242 (1), 132-147) was limited to the experimental values measured for protein backbone nuclei $(\mathrm{H}$ and $\mathrm{H} \alpha)$, the positions of which are more reliable than those of sidechain nuclei.

The PCSs for the copper(II) bound form of the type-1 copper protein Anabaena variabilis plastocyanin were taken from the project report by Robert Dagil (http://dagil.dk/bach.pdf), due to the unavailability of the supporting information of Jensen, M. R.; Hansen, D. F.; Ayna, U.; Dagil, R.; Hass, M. A.; Christensen, H. E.; Led, J. J., On the use of pseudocontact shifts in the structure determination of metalloproteins. Magn Reson Chem 2006, 44 (3), $294-$ 301. 
To extract the best-fit g-values from the experimental PCSs, and either the relationship from Eq.4 and Eq.5, the data were parametrically fitted using the equation

$\delta^{\mathrm{sd}}=\frac{1}{12 \pi r^{3}} \frac{\mu_{0} \mu_{\mathrm{B}}^{2} S(S+1)}{3 k T}\left[G_{a x}\left(3 \cos ^{2} \theta-1\right)+\frac{3}{2} G_{r h} \sin ^{2} \theta \cos 2 \phi\right]$

against the protein structures (Figure S5,S6). The best fit $G_{a x}$ and $G_{r h}$ values obtained for the three systems are reported in Tab. S1. The best fit $G_{a x}$ and $G_{r h}$ values can be used to predict $g_{z}$ and $g_{y}$, if the value of $g_{x}$, for instance, is fixed. Using the SE relationship (Eq. 5), for all systems $g_{z}$ is found to be close to the EPR values and comprised in the typical range for tetragonal copper(II) of 2.2-2.4, reported in the literature. On the contrary, using the QC relationship (Eq. 4), $g_{z}$ values as large as 2.5-2.8, far away from the observed EPR values, are obtained. 

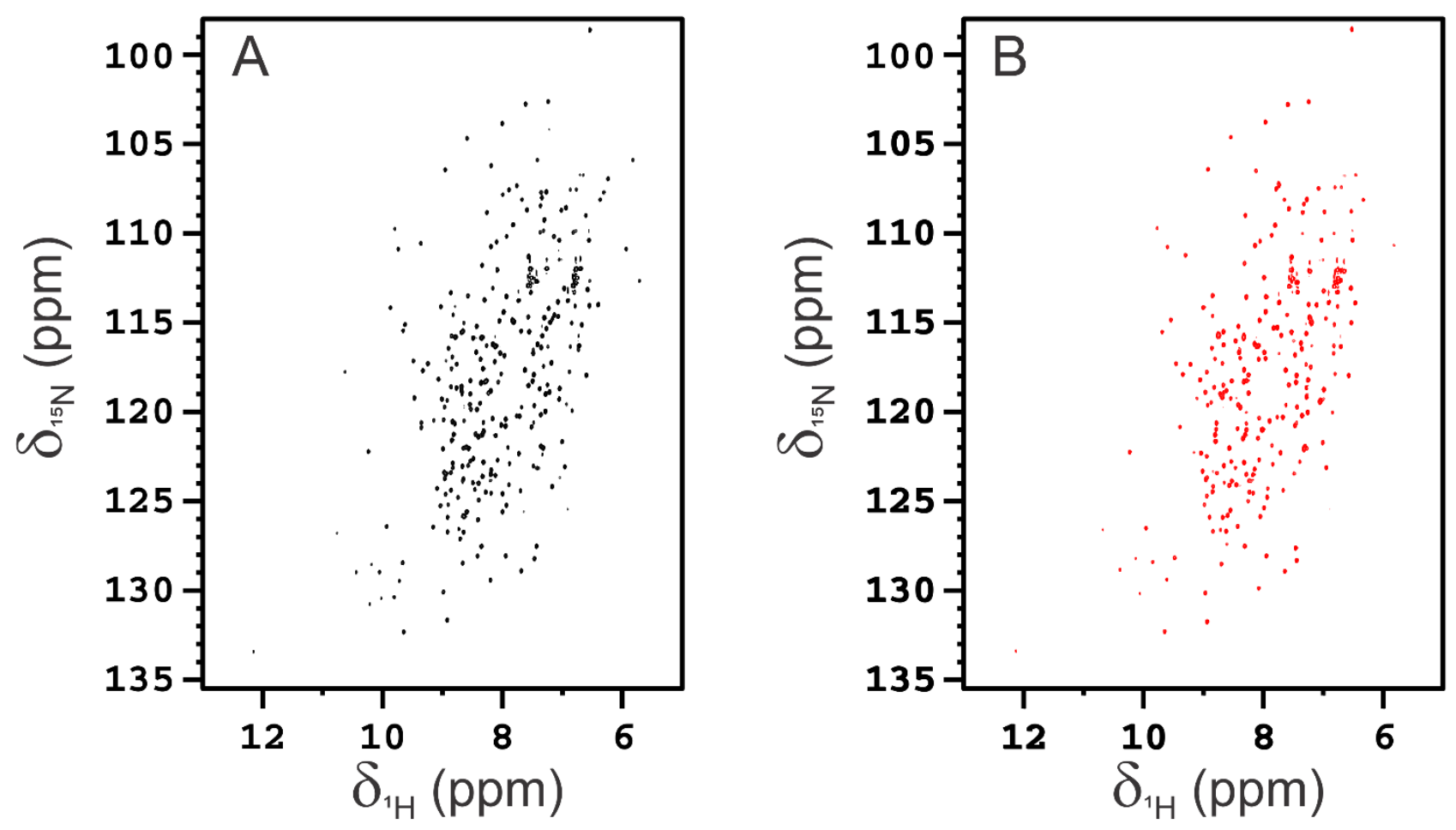

Figure S1. 2D ${ }^{1} \mathrm{H}_{-}{ }^{15} \mathrm{~N}$ HSQC NMR spectra of the zinc(II) (A) and copper(II) (B) substituted triple mutant of carbonic anhydrase II acquired at 298 $\mathrm{K}$ on a Bruker AVANCE III NMR spectrometer, operating at $950 \mathrm{MHz}{ }^{1} \mathrm{H}$ Larmor frequency. 


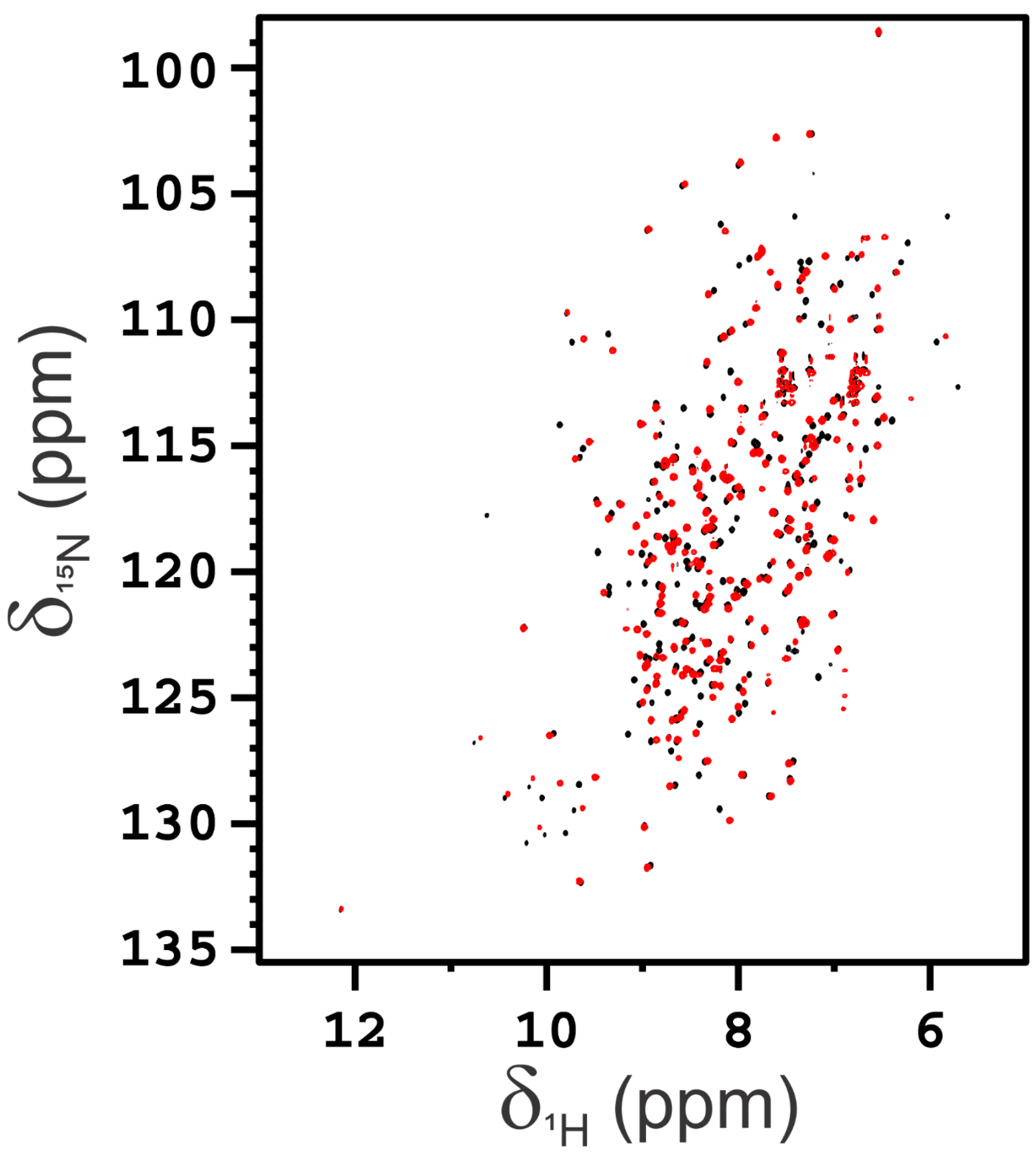

Figure S2. Superimposed 2D ${ }^{1} \mathrm{H}^{-15} \mathrm{~N}$ HSQC NMR spectra of the zinc(II) (black) and copper(II) (red) substituted triple mutant of carbonic anhydrase II acquired at $298 \mathrm{~K}$ on a Bruker AVANCE III NMR spectrometer, operating at $950 \mathrm{MHz}{ }^{1} \mathrm{H}$ Larmor frequency. 


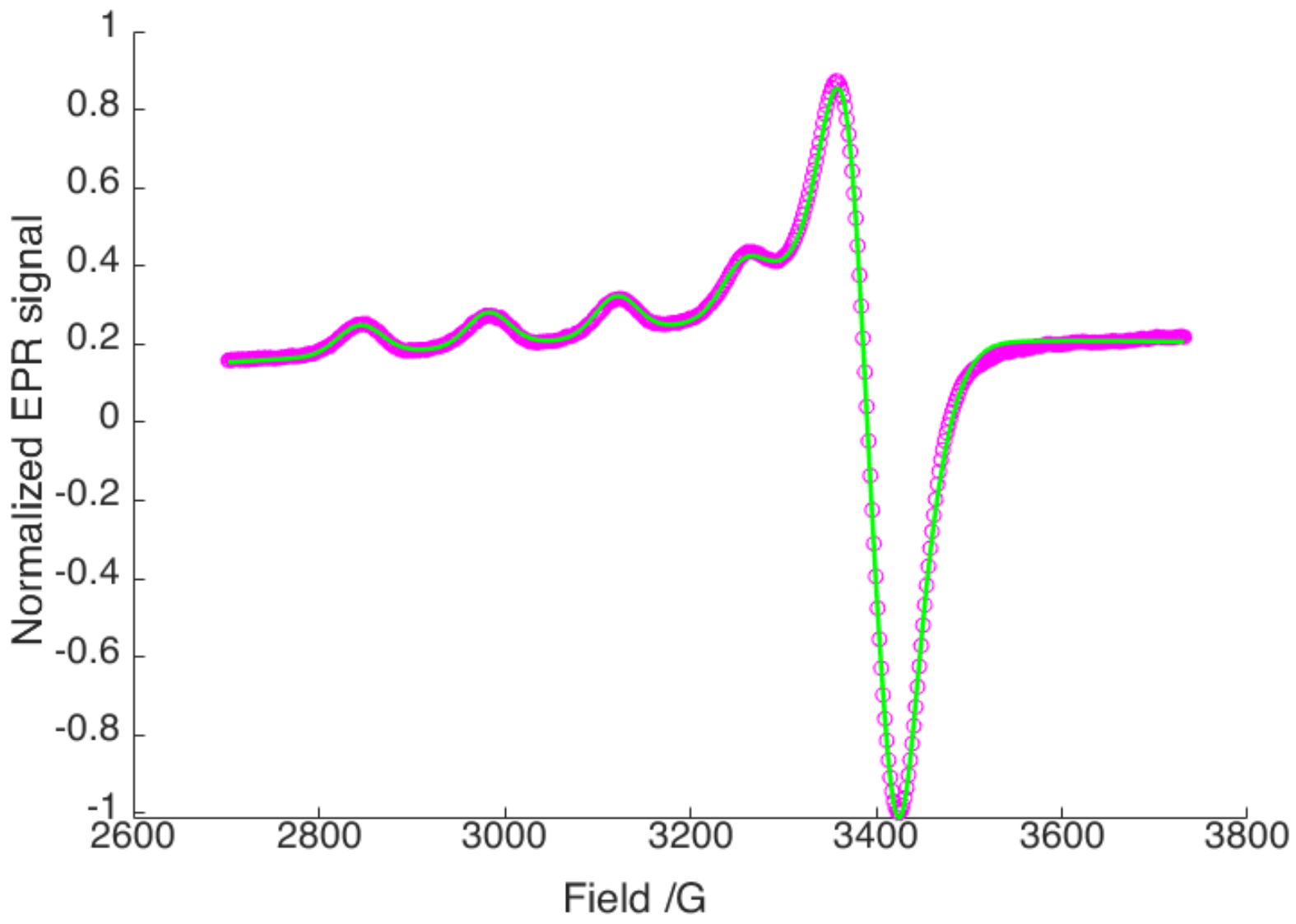

Figure S3. Room temperature solution EPR spectrum (magenta) of the triple mutant (H3N, H4N, H64N) of Cu+ ${ }^{2+}$-carbonic anhydrase II in complex with oxalate and best fit spectrum (green). 

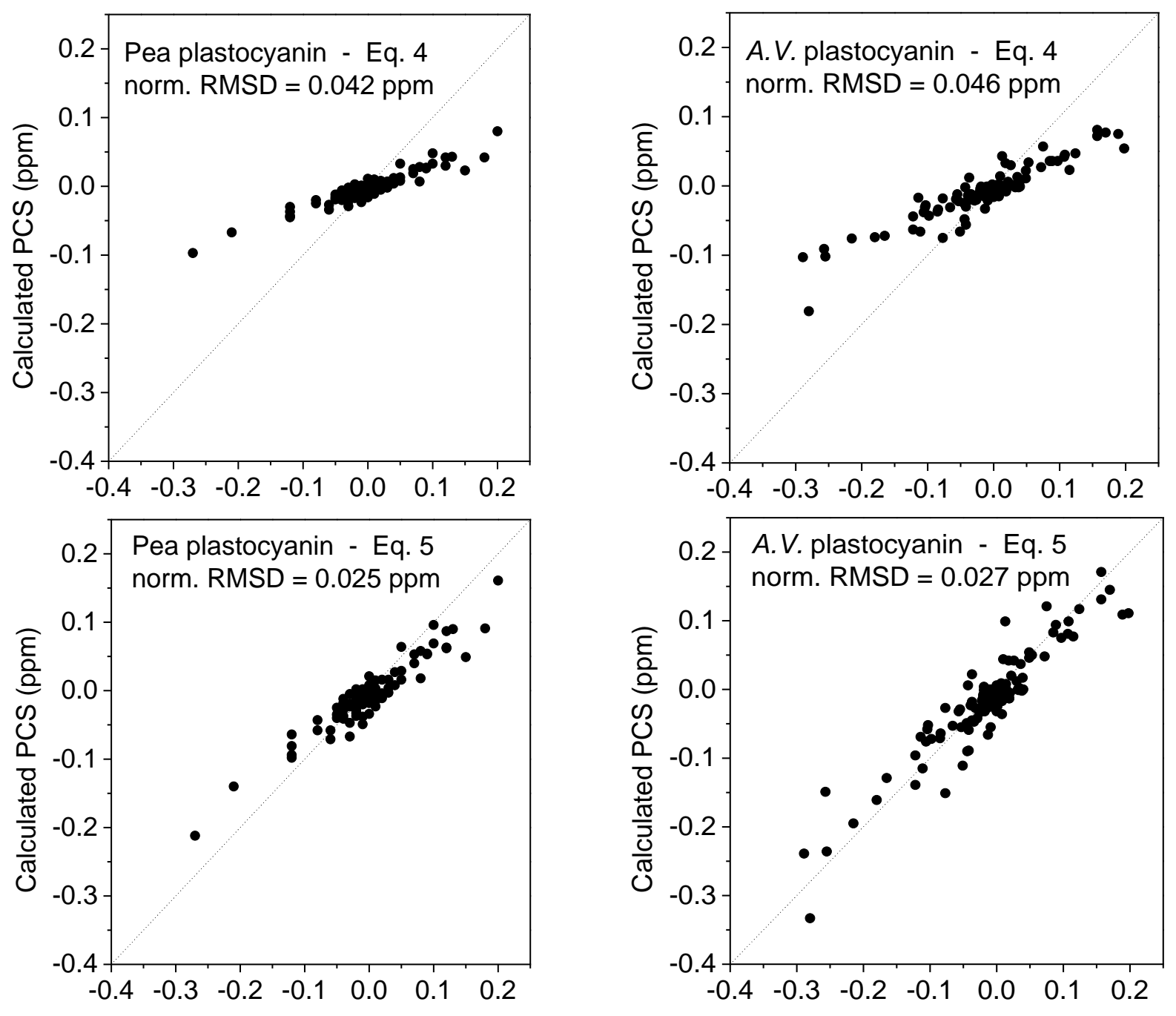

Figure S4. Agreement between experimental PCSs and values calculated with Eq. 4 or Eq. 5, as obtained from the EPR $g$-anisotropies and a 3parameters fit (the three Euler angles defining the main frame of the $\mathbf{g}$ tensor) against the protein structures. 

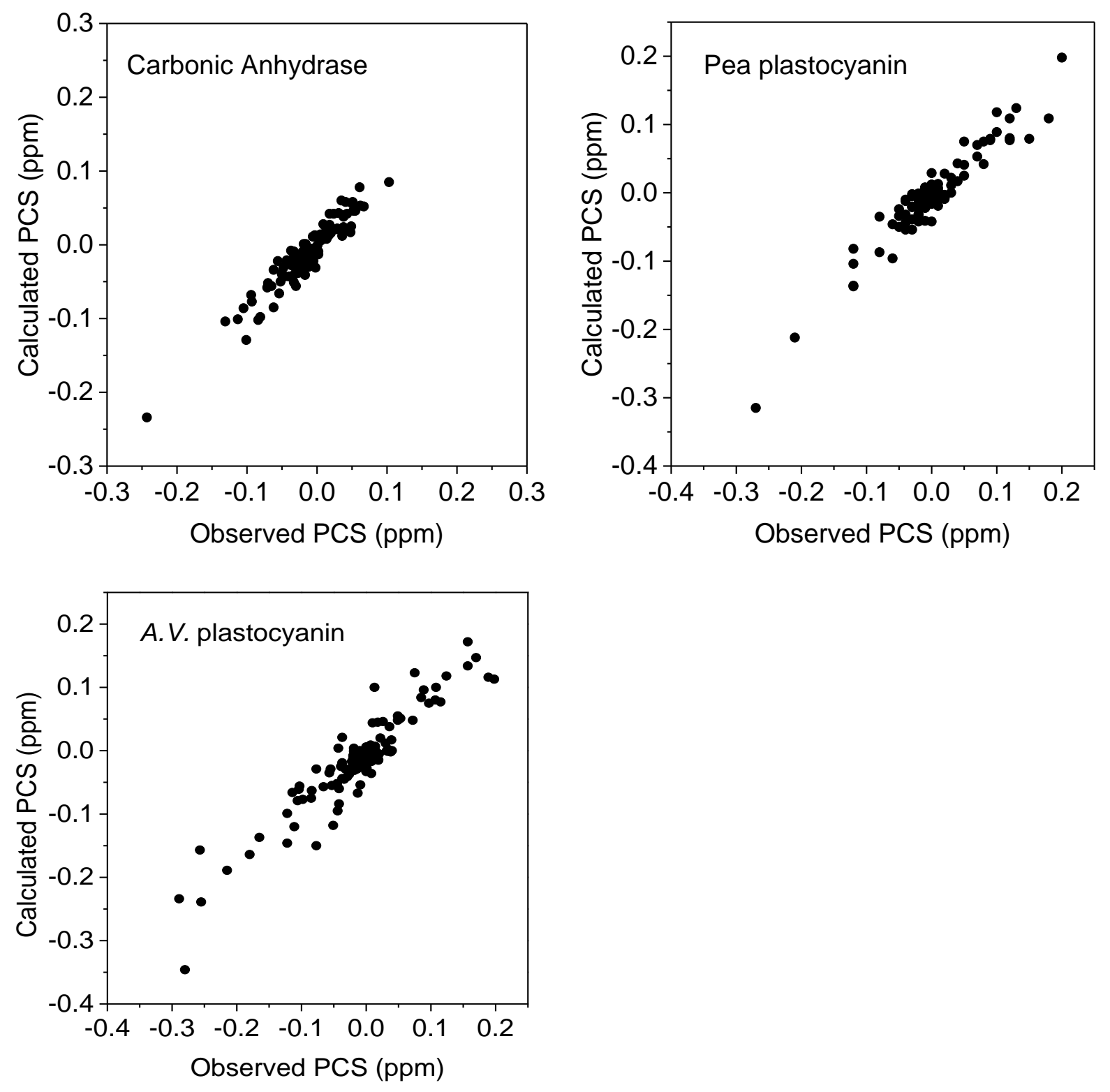

Figure S5. Agreement between experimental and calculated PCS, as obtained from a 5-parameters fit $\left(G_{a x}, G_{r h}\right.$, and the three Euler angles defining the main frame of the $\mathbf{g}$ tensor) against the protein structures. 


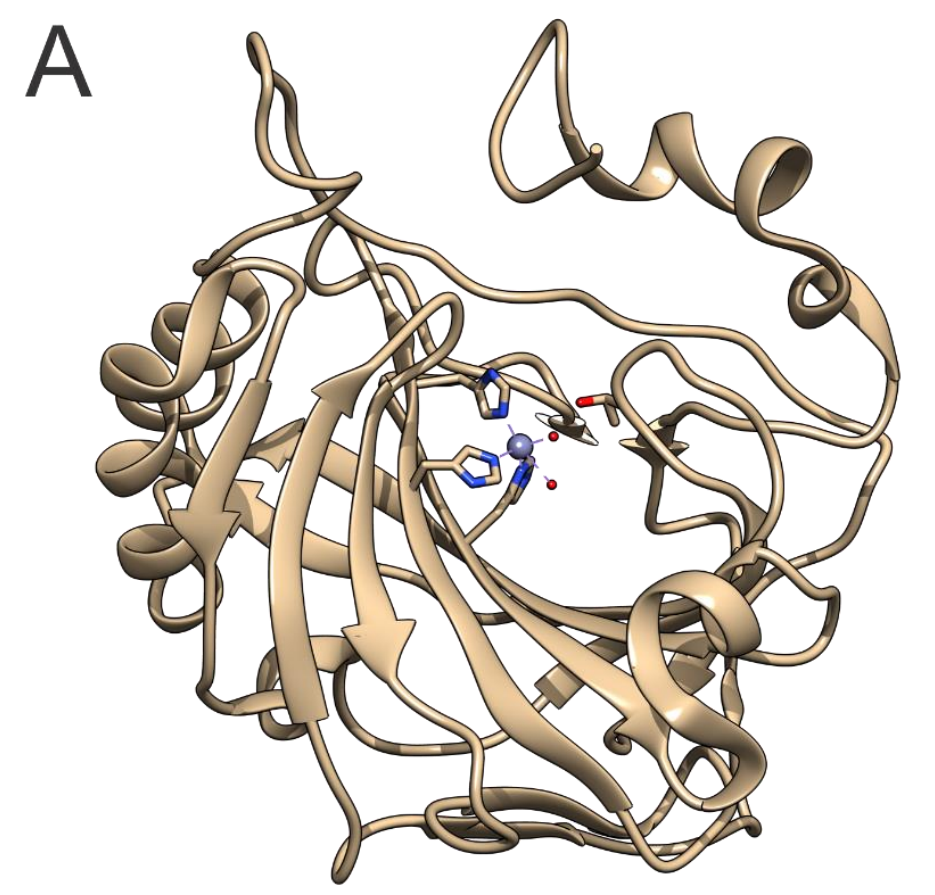

B

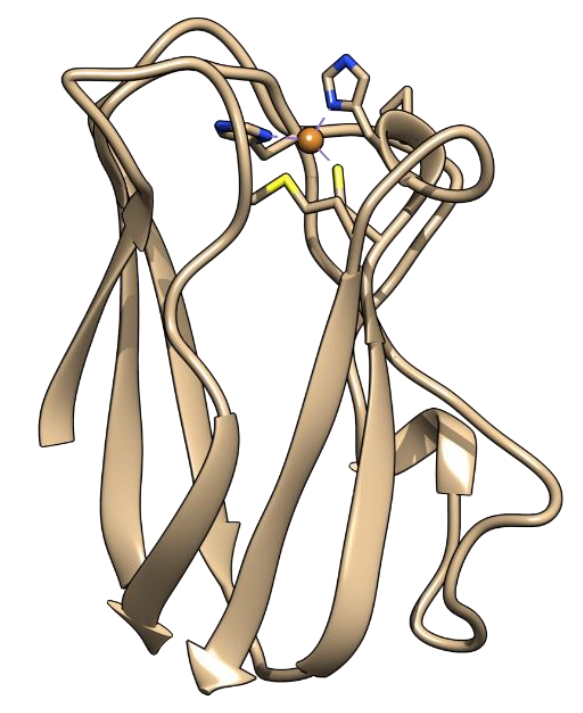

C

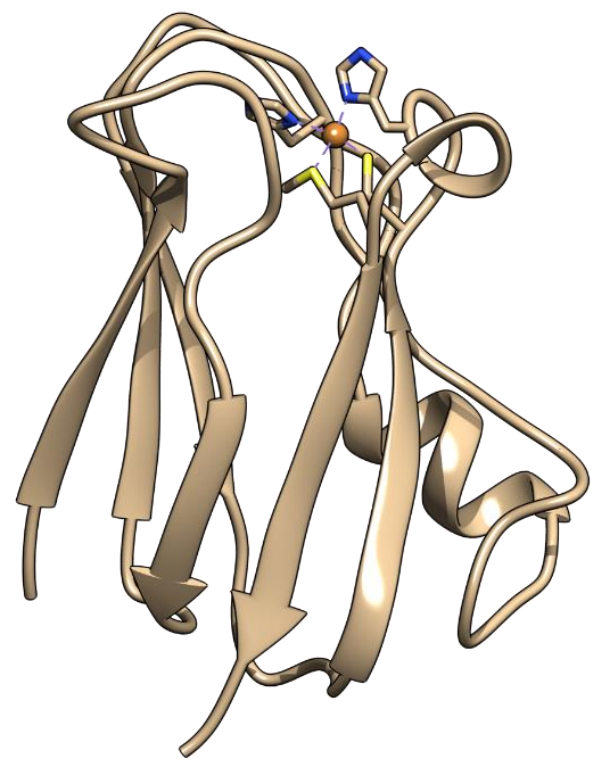

Figure S6. Protein structures used for the evaluation of the agreement between experimental and calculated PCS: (A) carbonic anhydrase II (PDB: 3KS3), (B) PEA plastocyanin (PDB: 9PCY), (C) A.V. plastocyanin (PDB: 2GIM). 


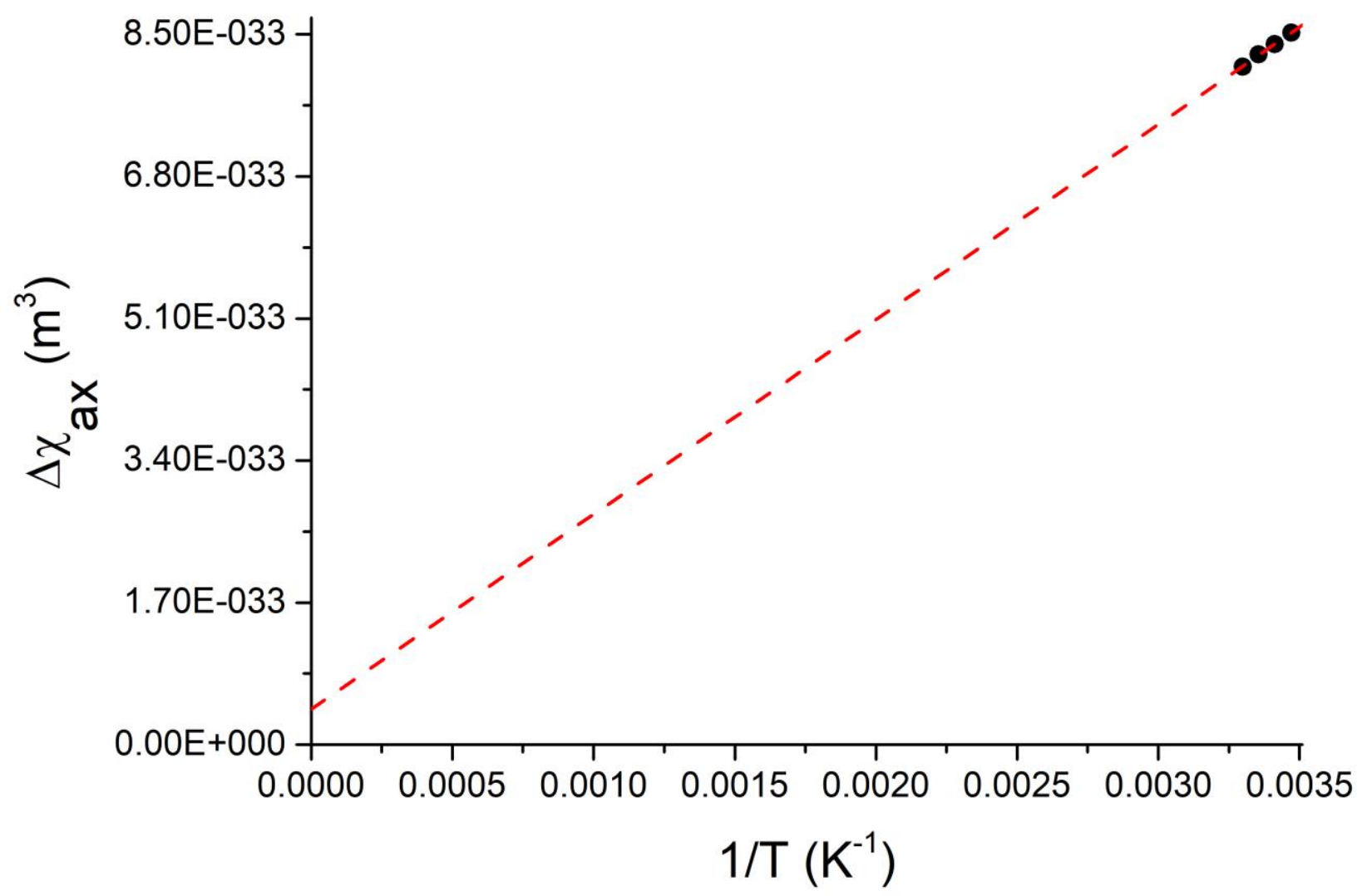

Figure S7. Plot of the $1 / T$ dependence of the $\Delta \chi_{a x}$ value. The $\Delta \chi_{a x}$ values were determined with the program FANTEN from the fit of experimental PCSs, measured at 288, 293, 298, and $303 \mathrm{~K}$, against the crystal structure of hCAII (pdb code: 3KS3). 
Table S1. EPR and PCS-derived g tensor parameters for the three investigated copper(II) proteins

\begin{tabular}{|l|l|l|l|}
\hline Protein & $\begin{array}{l}\mathrm{Cu}^{2+} \text {-carbonic anhydrase II - } \\
\text { oxalate }\end{array}$ & Pea plastocyanin ${ }^{1}$ & Anabaena variabilis plastocyanin $^{3}$ \\
\hline PDB & $3 \mathrm{KS} 3$ & $9 \mathrm{PCY}$ & $2 \mathrm{GIM}$ \\
\hline$g_{x}, g_{y}, g_{z}$ (experimental, from EPR) & $2.064,2.082,2.306$ & $2.042,2.059,2.226^{2}$ & $2.042,2.059,2.226^{2}$ \\
\hline$g_{x}, g_{y}, g_{z}$ from PCSs and Eq. 5 & $(2.05)^{4}, 2.12 \pm 0.01,2.37 \pm 0.01$ & $(2.04)^{4}, 2.10 \pm 0.01,2.28 \pm 0.02$ & $(2.04)^{4}, 2.06 \pm 0.01,2.23 \pm 0.01$ \\
\hline$g_{x}, g_{y}, g_{z}$ from PCSs and Eq. 4 & $(2.05)^{4}, 2.20 \pm 0.02,2.76 \pm 0.02$ & $(2.04)^{4}, 2.16 \pm 0.03,2.56 \pm 0.04$ & $(2.04)^{4}, 2.08 \pm 0.02,2.45 \pm 0.02$ \\
\hline$G_{a x}, G_{r h}($ experimental, from PCSs) & $1.26 \pm 0.02,-0.29 \pm 0.03$ & $0.91 \pm 0.05,-0.25 \pm 0.06$ & $0.77 \pm 0.03,-0.08 \pm 0.03$ \\
\hline$g_{e}\left(g_{z}-\frac{g_{x}+g_{y}}{2}\right), g_{e}\left(g_{x}-g_{y}\right)$ & $0.47,-0.04$ & $0.35,-0.03$ & $0.35,-0.03$ \\
from the experimental EPR values & & & $0.75,-0.07$ \\
\hline $\begin{array}{l}g_{z}^{2}-\frac{g_{x}^{2}+g_{y}^{2}}{2}, g_{x}^{2}-g_{y}^{2} \\
\text { from the experimental EPR values }\end{array}$ & $1.02,-0.08$ & $0.75,-0.07$ & \\
\hline
\end{tabular}

${ }^{1}$ Ubbink Eur. J. Biochem. 242, 132-147 (1996)

${ }^{2}$ for spinach plastocyanin at T=100 K. Penfield, K. W., Gewirth, A. A. \& Solomon, E. I. (1985) J. Am.Chem. Soc. 107, 4519-4529

${ }^{3}$ R. Jensen, D. F. Hansen, U. Ayna, R. Dagil, M. A.S. Hass, H. E. M. Christensen and J. J. Led, Magn. Reson. Chem. 2006; 44: 294-301

${ }^{4}$ The value of $g_{x}$ was fixed

\section{REFERENCES:}

1. Keller, R., The Computer Aided Resonance Assignment Tutorial. CANTINA Verlag: Goldau, 2004.

2. Cerofolini, L.; Staderini, T.; Giuntini, S.; Ravera, E.; Fragai, M.; Parigi, G.; Pierattelli, R.; Luchinat, C., Long-range paramagnetic NMR data can provide a closer look on metal coordination in metalloproteins. J. Biol. Inorg. Chem 2018, 23, 71-80.

3. Rinaldelli, M.; Carlon, A.; Ravera, E.; Parigi, G.; Luchinat, C., FANTEN: a new web-based interface for the analysis of magnetic anisotropy-induced NMR data. J Biomol NMR 2015, 61, 21-34. 4. Avvaru, B. S.; Kim, C. U.; Sippel, K. H.; Gruner, S. M.; Agbandje-McKenna, M.; Silverman, D. N.; McKenna, R., A Short, Strong Hydrogen Bond in the Active Site of Human Carbonic Anhydrase II. Biochemistry 2010, 49 (2), 249-251.

5. Stoll, S.; Schweiger, A., EasySpin, a comprehensive software package for spectral simulation and analysis in EPR. J Magn Reson 2006, 178 (1), 42-55. 
Table S2. PCSs measured for the copper-substituted human carbonic anhydrase II

\begin{tabular}{|c|c|c|c|}
\hline $\begin{array}{l}\text { Residue } \\
\text { number }\end{array}$ & $\begin{array}{l}\text { Residue } \\
\text { name }\end{array}$ & $\begin{array}{l}\text { Atom } \\
\text { name }\end{array}$ & $\begin{array}{l}\text { PCS } \\
(\mathrm{ppm})\end{array}$ \\
\hline 25 & GLY & $\mathrm{H}$ & 0.055 \\
\hline 26 & GLU & $\mathrm{H}$ & 0.029 \\
\hline 33 & ILE & $\mathrm{H}$ & 0.05 \\
\hline 35 & THR & $\mathrm{H}$ & 0.005 \\
\hline 39 & LYS & $\mathrm{H}$ & 0.001 \\
\hline 40 & TYR & $\mathrm{H}$ & -0.015 \\
\hline 41 & ASP & $\mathrm{H}$ & -0.033 \\
\hline 43 & SER & $\mathrm{H}$ & -0.001 \\
\hline 44 & LEU & $\mathrm{H}$ & 0.002 \\
\hline 47 & LEU & $\mathrm{H}$ & -0.01 \\
\hline 48 & SER & $\mathrm{H}$ & -0.029 \\
\hline 49 & VAL & $\mathrm{H}$ & -0.03 \\
\hline 51 & TYR & $\mathrm{H}$ & 0.008 \\
\hline 52 & ASP & $\mathrm{H}$ & 0.006 \\
\hline 54 & ALA & $\mathrm{H}$ & 0.009 \\
\hline 55 & THR & $\mathrm{H}$ & 0.052 \\
\hline 56 & SER & $\mathrm{H}$ & 0.041 \\
\hline 57 & LEU & $\mathrm{H}$ & 0.103 \\
\hline 59 & ILE & $\mathrm{H}$ & 0.061 \\
\hline 71 & ASP & $\mathrm{H}$ & 0.035 \\
\hline 72 & ASP & $\mathrm{H}$ & 0.031 \\
\hline 74 & GLN & $\mathrm{H}$ & 0.017 \\
\hline 76 & LYS & $\mathrm{H}$ & 0.048 \\
\hline 80 & LYS & $\mathrm{H}$ & -0.021 \\
\hline 81 & GLY & $\mathrm{H}$ & -0.021 \\
\hline 82 & GLY & $\mathrm{H}$ & -0.025 \\
\hline 84 & LEU & $\mathrm{H}$ & -0.028 \\
\hline 86 & GLY & $\mathrm{H}$ & -0.005 \\
\hline 87 & THR & $\mathrm{H}$ & -0.022 \\
\hline 102 & GLY & $\mathrm{H}$ & -0.01 \\
\hline 103 & GLN & $\mathrm{H}$ & -0.029 \\
\hline 104 & GLY & $\mathrm{H}$ & -0.056 \\
\hline 110 & ASP & $\mathrm{H}$ & 0.011 \\
\hline 114 & TYR & $\mathrm{H}$ & -0.01 \\
\hline 115 & ALA & $\mathrm{H}$ & -0.033 \\
\hline 116 & ALA & $\mathrm{H}$ & -0.084 \\
\hline 123 & TRP & $\mathrm{H}$ & -0.03 \\
\hline 125 & THR & $\mathrm{H}$ & -0.038 \\
\hline 126 & LYS & $\mathrm{H}$ & -0.027 \\
\hline 127 & TYR & $\mathrm{H}$ & -0.012 \\
\hline 128 & GLY & $\mathrm{H}$ & -0.008 \\
\hline 129 & ASP & $\mathrm{H}$ & -0.029 \\
\hline 130 & PHE & $\mathrm{H}$ & -0.019 \\
\hline 131 & GLY & $\mathrm{H}$ & -0.026 \\
\hline 132 & LYS & $\mathrm{H}$ & -0.043 \\
\hline 133 & ALA & $\mathrm{H}$ & -0.05 \\
\hline
\end{tabular}




$\begin{array}{llll}134 & \text { VAL } & \text { H } & -0.054 \\ 135 & \text { GLN } & \text { H } & -0.07 \\ 136 & \text { GLN } & \text { H } & -0.03 \\ 139 & \text { GLY } & \text { H } & -0.093 \\ 145 & \text { ILE } & \text { H } & -0.243 \\ 147 & \text { LEU } & \text { H } & -0.081 \\ 148 & \text { LYS } & \text { H } & -0.04 \\ 149 & \text { VAL } & \text { H } & -0.048 \\ 151 & \text { SER } & \text { H } & -0.033 \\ 152 & \text { ALA } & \text { H } & -0.02 \\ 156 & \text { LEU } & \text { H } & -0.006 \\ 157 & \text { GLN } & \text { H } & -0.003 \\ 159 & \text { VAL } & \text { H } & 0.038 \\ 160 & \text { VAL } & \text { H } & 0.029 \\ 161 & \text { ASP } & \text { H } & 0.012 \\ 162 & \text { VAL } & \text { H } & 0.049 \\ 163 & \text { LEU } & \text { H } & 0.02 \\ 165 & \text { SER } & \text { H } & 0.036 \\ 166 & \text { ILE } & \text { H } & 0.017 \\ 167 & \text { LYS } & \text { H } & -0.016 \\ 168 & \text { THR } & \text { H } & -0.005 \\ 170 & \text { GLY } & \text { H } & -0.019 \\ 171 & \text { LYS } & \text { H } & 0.014 \\ 175 & \text { PHE } & \text { H } & 0.067 \\ 176 & \text { THR } & \text { H } & 0.024 \\ 177 & \text { ASN } & \text { H } & 0.043 \\ 178 & \text { PHE } & \text { H } & 0.062 \\ 179 & \text { ASP } & \text { H } & 0.018 \\ 182 & \text { GLY } & \text { H } & 0.018 \\ 183 & \text { LEU } & \text { H } & 0.038 \\ 186 & \text { GLU } & \text { H } & -0.024 \\ 187 & \text { SER } & \text { H } & -0.027 \\ 188 & \text { LEU } & \text { H } & -0.031 \\ 191 & \text { TRP } & \text { H } & -0.02 \\ 195 & \text { GLY } & \text { H } & -0.052 \\ 203 & \text { LEU } & \text { H } & -0.105 \\ 208 & \text { TRP } & \text { H } & -0.113 \\ 211 & \text { LEU } & \text { H } & -0.062 \\ 213 & \text { GLU } & \text { H } & -0.036 \\ 216 & \text { SER } & \text { H } & -0.043 \\ 217 & \text { VAL } & \text { H } & -0.012 \\ 219 & \text { SER } & \text { H } & -0.018 \\ 220 & \text { GLU } & \text { H } & -0.022 \\ 221 & \text { GLN } & \text { H } & -0.02 \\ 222 & \text { VAL } & \text { H } & -0.062 \\ 225 & \text { PHE } & \text { H } & -0.046 \\ 226 & \text { ARG } & \text { H } & -0.065 \\ 227 & \text { LYS } & \text { H } & -0.017 \\ 229 & \text { ASN } & \text { H } & -0.026 \\ 230 & \text { PHE } & \text { H } & -0.071 \\ 231 & \text { ASN } & \text { H } & -0.032\end{array}$




$\begin{array}{llll}232 & \text { GLY } & \text { H } & -0.035 \\ 233 & \text { GLU } & \text { H } & -0.019 \\ 235 & \text { GLU } & \text { H } & -0.011 \\ 237 & \text { GLU } & \text { H } & -0.032 \\ 238 & \text { GLU } & \text { H } & -0.002 \\ 239 & \text { LEU } & \text { H } & -0.05 \\ 240 & \text { MET } & \text { H } & -0.094 \\ 241 & \text { VAL } & \text { H } & -0.131 \\ 242 & \text { ASP } & \text { H } & -0.101 \\ 250 & \text { LEU } & \text { H } & 0.051 \\ 251 & \text { LYS } & \text { H } & 0.038 \\ 253 & \text { ARG } & \text { H } & 0.045 \\ 254 & \text { GLN } & \text { H } & 0.006 \\ 255 & \text { ILE } & \text { H } & 0.001 \\ 256 & \text { LYS } & \text { H } & 0.002 \\ 257 & \text { ALA } & \text { H } & -0.037 \\ 258 & \text { SER } & \text { H } & -0.029 \\ 259 & \text { PHE } & \text { H } & -0.015 \\ 260 & \text { LYS } & \text { H } & -0.017\end{array}$

